\title{
Building a Social and Academic Online Bridge to Quantitatively- Rich College Coursework
}

\author{
Melissa Eblen-Zayas \\ Carleton College, meblenza@carleton.edu \\ Lin Winton \\ Carleton College, Iwinton@carleton.edu
}

Follow this and additional works at: https://digitalcommons.usf.edu/numeracy

Part of the Scholarship of Teaching and Learning Commons

\section{Recommended Citation}

Eblen-Zayas, Melissa, and Lin Winton. "Building a Social and Academic Online Bridge to QuantitativelyRich College Coursework." Numeracy 15, Iss. 1 (2022): Article 3. DOI: https://doi.org/10.5038/ 1936-4660.15.1.1408 


\title{
Building a Social and Academic Online Bridge to Quantitatively-Rich College Coursework
}

\begin{abstract}
We describe the online summer portion of a quantitative skills bridge program focused on helping students prepare socially and academically for the transition to college. College students are increasingly asked to employ quantitative skills across the curriculum, but students arrive at college with varied preparation. Further, those with the least preparation often encounter other challenges to social belongingness and navigating their institution. In response to these needs, our institution developed a bridge program aimed at students with a broad range of interests -- not just STEM, and the program has a significant focus on community-building as well as strengthening quantitative skills. The six-week summer online portion is followed by a face-to-face fall portion. Here we describe key design aspects of the online portion of the program: program goals and structure, selection and demographics of participants, and resources required to run the program. In addition, we share lessons learned that may be relevant for other institutions considering such a quantitative skills bridge program.
\end{abstract}

\section{Keywords}

online bridge program, quantitative skills preparation

\section{Creative Commons License}

\section{c) (7) (8)}

This work is licensed under a Creative Commons Attribution-Noncommercial 4.0 License

\section{Cover Page Footnote}

Melissa Eblen-Zayas is a professor of physics at Carleton College, and she previously served as Director of the Perlman Center for Learning and Teaching at Carleton. She co-designed and co-developed the Carleton Undergraduate Bridge Experience (CUBE) in 2016 and was the instructor for the program from 2016-2019.

Lin Winton is the Director of the Quantitative Resource Center at Carleton College and a lecturer in biology. She has been the instructor for the CUBE program since 2020. 


\section{Introduction}

Students' mathematical preparation for college and their facility with quantitative skills and quantitative reasoning affect their success on many fronts. A 2016 report by the National Center for Education Statistics showed that nearly one-third of students at public four-year institutions enroll in remedial math courses; of those, students who do not complete their remedial math requirements are twice as likely to drop out as those who are successful (Chen 2016). Quantitative preparation for college is particularly relevant for students who are underrepresented minorities (URM) and first-generation or lower income (FLI). These students often have $\mathrm{K}$ 12 educational experiences that do not match faculty expectations, creating disparities in outcomes such as course grades and representation and persistence across majors, particularly those that are more quantitatively demanding. Research confirms that racial and socioeconomic gaps in the early math preparation of students affect how well positioned students are for two-year or four-year college experiences (Lee 2012); these gaps also exist within highly selective institutions (Brown et al. 2017).

Bridge programs are one approach to addressing student quantitative skill preparation and the transition to college. While bridge programs are all offered in the period between the completion of high school and the beginning of in-residence college coursework, they are implemented in many different ways depending on institutional need and context. Meta-studies on the effectiveness of bridge programs remain inconclusive; the What Works Clearinghouse 2015 report on developmental bridge programs and What Works Clearinghouse 2016 report on summer bridge programs (without a focus on developmental coursework) found that most of the programs reported in the literature did not meet the data collection and evidence standards needed to assess the effectiveness of these programs. This may be due in part to the varied goals and implementation of the various programs that are classified as bridge programs.

In addition to outcomes, detailed descriptions of how bridge programs respond to institutional need and context are lacking. A 2017 review of 46 reports on 30 different STEM bridge programs by Ashley et al. noted:

When we surveyed the literature..., we were struck by how little information was presented about how to run the day-to-day activities of a bridge program. How much do these programs cost? How are students recruited and selected into the program? What is the average size of the program, who staffs the program, and who develops the curriculum? A team developing a bridge program would benefit from more information about program logistics.

This paper is a response to that request for details about bridge program logistics, with a focus on an online quantitative skills bridge program. In the wake 
of COVID-19, many institutions are reevaluating what role online programs might play. Reports of online bridge programs with a significant quantitative skills component primarily describe the math curriculum (Reisel et al. 2012; Jura and Gerhardt 2021) but do not describe how they also aim to foster a sense of belonging, which higher education institutions need to consider if they want their URM and FLI students to succeed. Several STEM-focused bridge programs that transitioned an on-campus program to online specifically noted that the online program did not foster connections among peers in the same way that the on-campus bridge program did (White et al. 2011; Brinkley et al. 2014).

We describe in detail the implementation of the online portion of the Carleton Undergraduate Bridge Experience (CUBE), a hybrid bridge program offered since 2016 that aims to review selected quantitative topics and skills that are typical in high school math courses, up through pre-calculus. CUBE begins in the summer before students' first years with a completely online, credit-bearing portion, followed by a traditional face-to-face course for the first half of the fall term. The program is designed to be high-touch and foster a sense of belonging (Eblen-Zayas and Russell 2019). In developing CUBE, we wanted to provide the benefits of a bridge program that both developed academic skills and fostered community, in a context that did not require students to be on campus and forgo summer work or family commitments, which are of particular relevance to FLI students.

This paper provides an overview of program goals and structure, participant selection, and resources required, as well as lessons learned over the past five years, with the goal of providing a case study that might be valuable for other institutions developing such programs.

\section{Institutional Context}

Our institution, a residential liberal arts college of about 2000 undergraduates in rural Minnesota, has embraced quantitative reasoning $(\mathrm{QR})$ across the curriculum (Rutz and Grawe 2017), with QR defined as using numerical or quantitative evidence to support an argument. Students must complete three courses that include a quantitative reasoning encounter (QRE) for graduation. However, the college offers no remedial math or QR courses; math offerings begin at the level of Calculus 1. While many students will not pursue majors that require calculus, instructors of QRE courses traditionally assume that students are proficient with math skills through pre-calculus (and, increasingly, introductory statistics and Microsoft Excel).

In recent years, faculty have sensed that some students struggled in courses with a QRE component because their underlying quantitative skills (QS) were weak, but without any campus-wide effort to address the preparation of these students, faculty members have worked independently to support students in their 
own courses. As one approach to address the variation in student preparation at an institutional level, we have developed a bridge program - the only bridge program at our institution - that focuses on reviewing and strengthening student QS. Importantly, unlike many bridge programs focused on pathways into STEM fields, this program is focused on demonstrating the relevance of QS in a variety of disciplinary contexts, consistent with our institution's commitment to QR across the curriculum.

\section{Program Goals and Structure}

CUBE aims to: 1) strengthen students' quantitative skills in topics that are covered in high school math classes through pre-calculus and relevant across disciplines, 2) introduce students to study skills and help-seeking approaches for navigating college, and 3) give students opportunities to begin building connections with peers and other members of the college community (faculty, staff, and alums). The program comprises a unique blend of high-touch online and face-to-face learning experiences designed to prepare students for their time in a residential liberal arts setting. The academic components of the program aim to strengthen students' quantitative skills; details on how the specific quantitative skills were chosen can be found in Eblen-Zayas and Russell (2019). We focus here on the preparatory and day-to-day logistics, for those interested in implementing such a program.

The course is credit-bearing; students who complete both the summer and fall components of the program earn six academic credits, the equivalent of a typical course at our institution. Creating a credit-bearing program was more logistically challenging than one for which students earn no credit, but we prioritized this for two reasons. One, the program provides students with a credit cushion that allows them to drop a course or take a lighter load and remain on track with credits for graduation. (Data on student pre-matriculation credits can be found in the "Participant selection" section). Two, we thought that earning credits at no additional cost to the student would create more buy-in. Indeed, when we ask for the students' reasons for applying as part of the program application, we have found that $17 \%$ of applicants mention free or early credits as part of their motivation.

Carleton culture values student collaboration on course work. Peers occupy significant instructional support roles on campus such as course prefects (similar to supplementary instruction leaders), lab assistants, and peer support in campus tutoring centers (mathematics, QS/QR, and writing). In CUBE, we introduce students to these values by fostering meaningful peer interactions with both academic and non-academic purposes, most notably through having more advanced students serve as "coaches" for teams of four to six students. These teams, assigned based on scheduling availability, have synchronous weekly meetings. The coaches provide instructional support, similar to the peer instructional support available 
during the academic year, and talk with the participants about what to expect in their first year.

A challenge in designing the program was to balance providing sufficient structure with flexibility, given that students have many competing demands on their time (e.g., jobs, volunteer work, family care). One way in which the program design tried to strike this balance was by having regular weekly expectations and activities that were heavily, but flexibly, scaffolded. For example, many of the activities included turning in materials for feedback and then revising and resubmitting them. If a student missed turning in the materials originally, they missed the opportunity for early feedback, but the student could still turn in the work when their peers turned in revised work, without any penalty except for the loss of early feedback. Nearly all activities provided opportunities for revision and resubmission. For activities where the focus was on real-time engagement, the program was designed so that students only needed to participate in some fraction of the activities throughout the summer.

We were careful to design the summer program to have a clear, recurring weekly structure to help students navigate the online learning environment, particularly because the summer portion is substantially asynchronous. This structure was emphasized repeatedly: in the learning management system, the syllabus, and briefly in the welcome video that students view as part of their first assignment. Such transparent course organization reduces the cognitive resources that online learners have to expend on tracking course components, which in turn fosters student success and allows students to more fully devote cognitive resources to engaging with course content and activities (Boettcher and Conrad 2016; Darby 2019).

We designed the weekly format to have frequent touchpoints with students (Fig. 1). Many of these are ungraded, but they allow the instructor and coaches to identify potential problematic patterns in engagement early in the course, and provide feedback. Thus, students are made aware that the instructional team is paying attention to how they are engaging with course activities. Students are also getting personalized feedback to help them adjust early and understand the course expectations, before their college habits are established. 


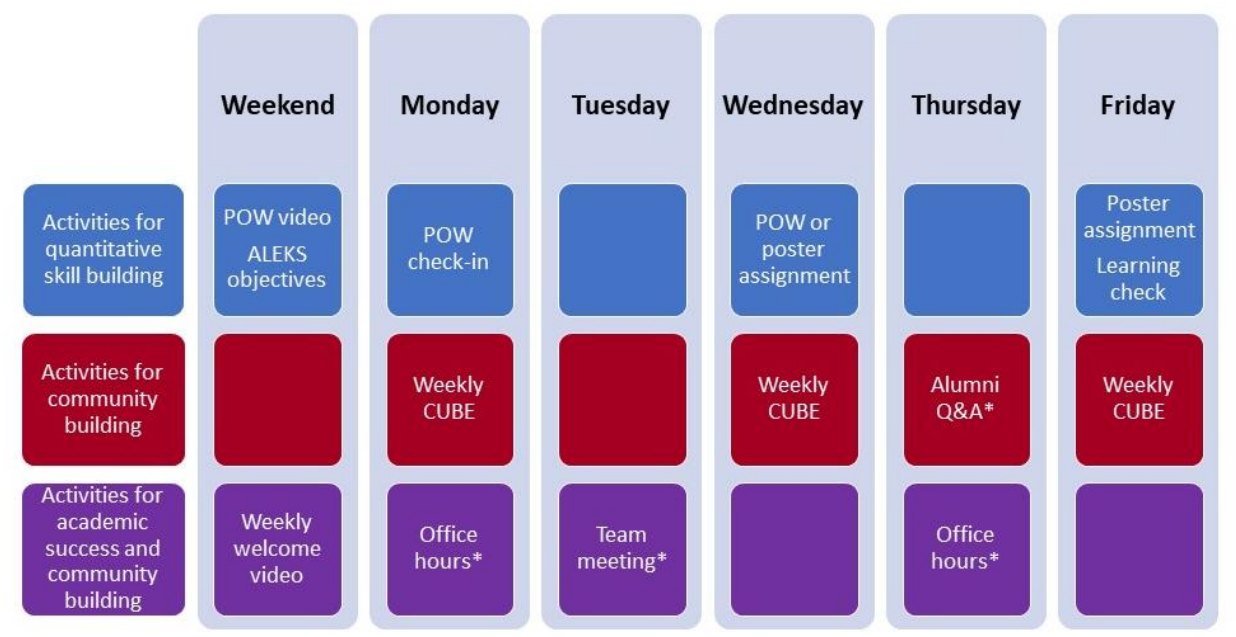

Figure 1. Regular weekly schedule with activities listed according to the program goals they are designed to support: top row supports quantitative skill building, middle row supports community building, bottom row supports both academic success and community building. The activities with the $*$ are activities that occur via synchronous videoconferencing.

Each week begins with a weekly welcome video by instructional faculty that introduces the upcoming topics and the activities they will complete for a six-week campus data project (details in Eblen-Zayas and Russell [2019]). The weekly welcome video is also an opportunity for faculty to positively reinforce student behaviors from the previous week such as coming to office hours, meeting deadlines, and responding thoroughly to assignment prompts. Finally, these videos are a chance to remind students about effective time management skills, institutional deadlines such as course registration, and other "just-in-time" advice.

Students are given a new set of quantitative learning objectives each week to work toward in the online homework system (ALEKS), as well as instructional videos that are designed to support the Problem of the Week (POW) or the campus data project. Figure 2 provides an overview of the weekly content for these activities. Before beginning their POW, students do a "check-in" assignment, which consists of two to three brief questions requiring them to apply the QS for that week in various contexts. These check-ins give students and the instructional team a sense of where they are as they begin the week.

Perhaps the most meaningful opportunity for engagement each week is the synchronous team meeting, where program participants collaborate on the weekly assignments and socialize with a small group of peers and a peer coach. These team meetings occur early in the week before students are expected to submit either their POW assignments (due on Wednesdays) or the campus data project assignments (usually due on Fridays). 


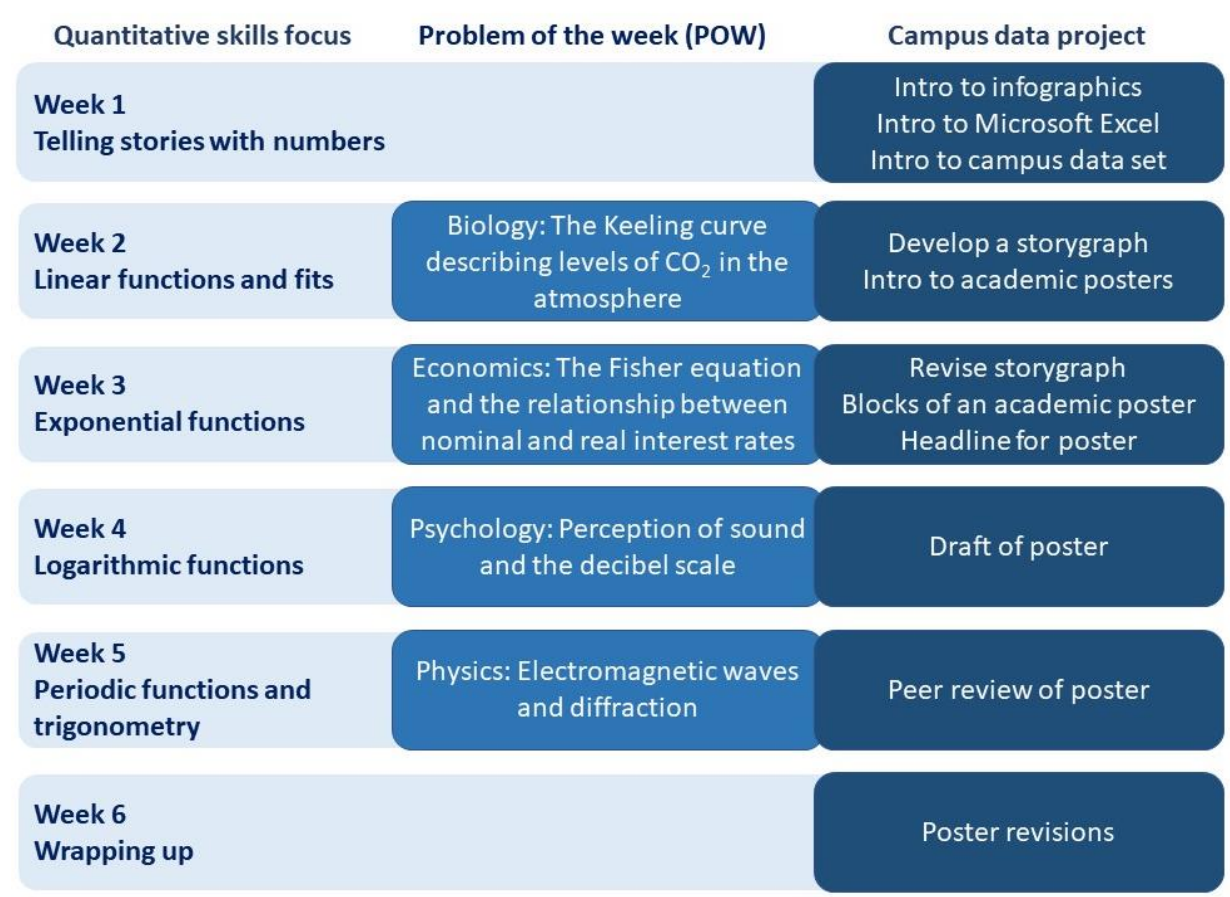

Figure 2. Quantitative skills focus, Problem of the Week (POW) topic, and campus data project assignments for each of the six weeks of the program.

When students submit the POW, they are also asked about their confidence in the topic, what questions they still have, and their help-seeking behavior while working on the POW, including which peers and instructors they consulted as resources. These questions are designed to foster metacognition and normalize seeking help from peers and instructors. The week wraps up with a "learning check" - two to three questions similar to the check-in at the beginning of the week - that gives students a final opportunity to test their understanding of the week's quantitative topic. If there are common difficulties, the instructor can create a screencast that addresses these.

In addition to the POW, each week includes scaffolded activities for the campus data project that aims to help students learn how to tell stories about and with numbers. For this project, all students in the course work with a common large campus data set (11 variables, $\sim 1100$ rows) that includes data about campus wind turbine energy production, energy consumption in eight different buildings - both academic buildings and dorms - and temperature data from a campus weather station, over the course of two years. The data set is large enough to provide a range of questions for students to explore, without being overwhelming. Students work in pairs or groups of three to develop and revise graphs and text that are combined into an academic poster. Students revise their poster multiple times throughout the 
program, then present it at a poster session open to the campus when they arrive in the fall.

Other opportunities for engagement include twice-weekly office hours with instructional faculty, weekly optional office hours with their team coach, and a weekly question and answer (Q\&A) session with a panel of two to three alumni. In these panels, alumni share their experiences at Carleton, their pathways since graduating from Carleton, and how they have used quantitative skills in a wide variety of career paths. For many students, the alumni Q\&A sessions are their introduction to the benefits of a college alumni network, which is especially strong at Carleton. Many Carleton graduates get their first jobs or internships through alumni connections, but students who are the first in their families to attend college or are unfamiliar with private college culture are less likely than non-firstgeneration students to use this resource to find employment (Eismann 2016).

Students also respond to social media prompts (see Fig. 1 "Weekly CUBE") that are posted three times a week and designed to foster informal discussions of non-academic topics. Weekly CUBE prompts might ask, "What song is at the top of your playlist this week?" or "What is your superpower?" These allow students to get to know each other informally, and sometimes coaches or the instructor will also respond to these prompts. To prepare for the program every year, coaches revise these prompts, which keeps them relevant. In recent years, we have used the chat program Slack for these interactions. This gives students a space outside the learning management system where they can communicate less formally, respond with .gifs and emojis, and interact in real-time.

One of the benefits of this program that we did not fully realize when designing it is the opportunity for students to develop basic proficiency working with Microsoft Excel, which they use in some of their POWs and heavily for the campus data project. Carleton faculty who use Excel in their classes often assume that students know how to use it and thus do not spend class time introducing it, but we find that at least 50\% of CUBE students each year have never used Excel (or any similar program, such as Google Sheets). Through an institutional license, all students at Carleton have free access to Microsoft 365, which allows them to use Excel in their browser or download it onto their machine. We worked with Academic Technology to identify a few short videos on LinkedIn Learning (also through an institutional license) that each focus on one or a few skills in Excel, from entering and manipulating data tables to using basic formulas and creating simple graphs. Students view these videos in the first week, and Excel use is scaffolded throughout the six weeks of their campus data project assignments.

The in-person fall course meets once a week for the first half of the term. This course provides an opportunity for students to work in-person with the same teams that they collaborated with over the summer, to make final revisions and preparations for the poster session. The instructional faculty advertises the poster 
session through campus-wide channels as well as personally to key faculty, staff, and student groups such as chairs of departments in which students have expressed interest, the faculty director of the STEM success program, the TRIO student success program, and the Sustainability office (which provides our data set). The fall course continues to provide opportunities to connect students with the campus community through visits to relevant campus offices such as the Career Center and helps cement some of the early connections that are initiated during the summer. In addition, the fall course includes a brief unit on probability and descriptive statistics, which are broadly relevant topics that we were not able to include as one of the weekly topics for the POW during the summer.

\section{Participant Selection and Demographics}

Our process for inviting and selecting participants is described briefly in EblenZayas and Russell (2019). We elaborate on key details here and provide demographic data from the first five years of the program. In late May each year, domestic students with SAT Math (or ACT converted) scores in the lowest quartile for the incoming class (usually below 650) receive an invitation to apply for the program; this comprises about 150 students per year. We chose to recruit only domestic students so that we could ship computers and Wi-Fi hotspots if needed, and to avoid having students who are in drastically different time zones for synchronous team meetings. Each year, 40-50 of the 150 invitees submit an application. The online application consists of two components: short answer questions that gauge students' interest, motivation, and availability to participate, and a quantitative assessment. For the quantitative assessment, we use the diagnostic associated with the Prep for Calculus course in ALEKS. Of the applicants, we select no more than 24 students per year. The summer online portion of the program is theoretically scalable to a larger cohort (given concomitant increases in staffing), but the 24-person cap is driven by a desire to have an intimate class size for the fall portion of the program.

Selection of students comprises two phases. First, student scores and time spent on the ALEKS diagnostic, combined with SAT/ACT Math scores, are used to evaluate students' quantitative proficiency with skills that CUBE is designed to cover. Second, we conduct a holistic review of their written materials that focuses on their confidence in and previous experience with mathematics, and incorporates input from our other campus support programs (TRIO-SSS, Posse, and Carleton's STEM success program, FOCUS), in which students may also be participating. This collaborative approach attempts to strike a balance between meeting the needs of individual students and "spreading out" support, so that as many students benefit from our small network of campus programs as possible. While our primary selection criterion is students' quantitative proficiency, because these other 
programs focus on recruiting students of races that are underrepresented at Carleton (FOCUS) or who are the first in their family to attend college and/or lower-income (TRIO-SSS), these selection criteria become part of our selection process. Our intent is to select students based on direct evidence related to their quantitative skills, with special consideration for those who seem likely to struggle to find community at a private, predominantly white institution like Carleton. This selection process continues to evolve as we understand the outcomes of our program and as student needs change.

Table 1 describes the 2016-2020 cohorts of CUBE students (total of 92 students) compared to the rest of the student body on race, ethnicity, socioeconomic measures, and selected academic measures. Compared to the rest of the incoming class, CUBE students were significantly more likely to be Black, first-generation, or Hispanic; significantly less likely to be Asian, International (as expected, given that we recruited only domestic students), or male; and had a higher average percent of financial need (77\% vs. $38 \%$ ), fewer pre-matriculation credits (9 vs. 18), and lower Math SAT (or converted ACT) scores (by 116 points). A gap in SAT/ACT Math scores is expected, as these scores factored heavily into our recruitment and selection process, but the size of the gap is notable. Consistent with our effort to make the program appealing to students with a broad range of interests, we found that the five top areas of academic interest for CUBE participants were biology, political science, environmental studies (an interdisciplinary program that includes coursework in the social sciences, sciences, and humanities), economics, and psychology.

Table 1

Demographics of CUBE vs. Non-CUBE students, 2016-2020 cohorts

\begin{tabular}{lcc}
\hline Variable & CUBE & Non-CUBE \\
\hline Asian & $7 \%$ & $16 \%$ \\
Black & $48 \%$ & $7 \%$ \\
First-generation & $38 \%$ & $11 \%$ \\
Hispanic & $27 \%$ & $8 \%$ \\
International & $1 \%$ & $10 \%$ \\
Male & $33 \%$ & $50 \%$ \\
Percent financial need & $77 \%$ & $38 \%$ \\
Pre-matriculation credits & 9.1 & 17.8 \\
Math SAT & 600.1 & 716.4 \\
\hline
\end{tabular}

Note: Higher percentages or values in each category are shaded. 
The gap in pre-matriculation credits (credits from AP, IB, or other collegelevel coursework completed in high school) underscores our priority of making CUBE credit-bearing. The six credit hours that students earn for completing the program represents a $67 \%$ reduction in the credit gap between CUBE students and their peers. This "credit cushion" becomes especially relevant if students struggle in their first year and need to drop a course but also need to stay on track to graduate, maintain financial aid eligibility, or preserve the flexibility to study abroad.

\section{Resources for Supporting the Program}

Bridge programs are typically offered at no cost to students to make them more accessible, and some bridge programs pay students a stipend for their participation to offset lost wages from summer work. For on-campus bridge programs, institutions must commit significant resources to cover the cost of room and board for student participants, faculty and staff time, and a full slate of program activities each day. An online bridge program, where students participate while still at home, requires a smaller investment of resources because there are no room and board costs for participants, and far less staffing and programming is required. The online mode also allows students to still work and fulfill community roles such as caring for family members; this flexibility is further enhanced if the program is asynchronous. Thus, our program design has always made online asynchronous engagement the default, with only select components being synchronous.

We have found that the number of staff required for online and in-person bridge programs are similar. Our program is led by a faculty member for whom teaching in the bridge program counts towards their total annual teaching load and three to four peer coaches - students who are rising sophomores, juniors, or seniors. Coaches play multiple roles including learning assistant, new student advisor, and tech support. These students are hired full-time ( 40 hours/week) for the duration of the six-week program, as well as a few additional weeks in advance of the start of the program to refresh and troubleshoot online material. The program also benefits from significant support from the academic technology (AT) staff. This is considered part of their usual duties to support technology-enhanced learning and teaching, and there is no cost to the program for AT staff time.

An online program does require additional resources in terms of providing internet access and computers to students at home. To ensure equitable access, we shipped computers and Wi-Fi hotspots to program participants who needed them (as determined by an intake form that students filled out upon acceptance, and as needed throughout the program), and students returned these devices when they arrived on campus in the fall. The other major program expense is the ALEKS licenses, which cost approximately $\$ 25 /$ person. An ALEKS license must be 
provided for every applicant, not only those who are accepted, so that applicants can complete the diagnostic assessment. This has the benefit of providing every applicant access to the ALEKS platform for the duration of the summer, regardless of whether they are accepted into the program.

\section{Lessons Learned}

Through the first five years of CUBE, we have learned a number of lessons relevant for others who are considering implementing an online bridge program.

\section{Lesson 1}

Students value the social connections with alumni, coaches, and their teams. When we initially designed the program, we identified multiple benefits of having students work in teams with peer coaches. Working in small groups allowed students to get to know each other well and made it less difficult to accommodate the varying schedules that students had. The coaches give students an early introduction to the kind of peer support that is common and necessary for learning at Carleton. In addition, the coaches can share their experiences at Carleton and answer questions that the incoming students have about the transition. We make a concerted effort to recruit coaches who have a combination of strong quantitative skills, community-building skills, and backgrounds similar to our CUBE students. Students report that the social connections they form, especially with students on their teams and in their campus data project groups, are valuable and persist beyond the course. One student reported on their end-of-program evaluation, "My friends from CUBE are the people I am friends with now!" Other students have noted that CUBE "provide[d] me with a community to go to as soon as I arrived on campus" and that CUBE "made the adjustment a lot less difficult."

When we created the program, the weekly Q\&A with alums about their time at Carleton and their experiences after Carleton was added as an afterthought, to encourage students to consider the career relevance of quantitative skills in many different fields. After the first year of CUBE, seven students participated in a focus group interview about their experiences with CUBE. When asked about the most helpful aspect of the program, the element mentioned most often was the alumni panels ( 4 out of 7 students). In particular, the students noted that these panels helped them understand what it is like to be Carleton students and the options available after graduating. Over time, we have found that recruiting alums who are 5-15 years beyond graduation ensures that the alums have established themselves in their careers, but they are not too far removed from their experience on campus. Despite concerted effort, the demographics of the alumni volunteers do not reflect the students in CUBE, so alumni recruitment is an ongoing area for improvement. 


\section{Lesson 2}

The program increases interest in co-curricular academic experiences, but not QR class-taking or grades. At the beginning of each academic year, all incoming Carleton students complete one of two surveys on how they perceive their preparation for and interest in both the academic and non-academic aspects of college. (The CoFHE Survey of New Students [CSNS] is conducted in evennumbered years; the HERI CIRP Freshman Survey [HCFS] is conducted in oddnumbered years.) We collaborated with the Institutional Research and Assessment Office to conduct a comparison between CUBE and non-CUBE students using propensity score matching based on SAT Math scores, race, first-generation status, and family income, as all of these variables are significantly different for CUBE students than Carleton students in general. Based on independent sample t-tests for relevant survey items, we found on both surveys that CUBE students were more likely to be interested in doing research with a faculty member than the matched comparison group (CSNS 0.26 out of 4 points, $n=52, p=0.01$; HCFS 0.25 out of 5 points, $n=29, p=0.09$ ). In an analysis conducted in 2018 using data from the campus Career Center, we found that CUBE was a significant predictor of whether students would apply for internships or externships $(0.33 \pm 0.1, n=18, p<0.01)$. Taken together, our findings indicate that CUBE students are more likely to be interested in academic opportunities that Carleton offers outside of the classroom, when compared to demographically similar students who do not participate in CUBE. Given the under-representation of BIPOC and FLI students in academia and leadership roles across job sectors, and the formative role that internship and research experiences can play in a student's self-efficacy and path during college, these exciting findings warrant further consideration.

CUBE students also showed an increased belief in their ability to learn on their own ( 0.18 of 4 points, $n=52, p=0.08$ ) and likelihood to ask for help when they need it ( 0.16 of 4 points, $n=49, p=0.26$ ), but these differences were not statistically significant. Items for which there was little effect size and differences were not statistically significant were related to affective dimensions (curiosity, confidence, motivation), health, social interactions, preparation to navigate college (e.g., choosing classes, living with a roommate), and abilities in different disciplines. For these items, most CUBE students tended to rate themselves as average or above average (3-4 on a 5-point scale).

Although CUBE students did not indicate greater preparation to use quantitative tools than non-CUBE students on their first-year surveys $(n=45$, $p=0.25$ ), all students who filled out end-of-program evaluations either agreed or strongly agreed that CUBE helped improve their quantitative skills $(n=29)$. Because the first-year surveys are conducted late in the summer before the academic year begins, when students are in the CUBE program, quantitative-related items on the first-year survey data are difficult to interpret for CUBE students. 
On their end-of-program evaluation forms, many students express thanks for the opportunity to refresh their math skills before Carleton, and some articulate specific problem-solving strategies that have stuck with them. For example, one student said, "The ALEKS we did helped to clarify some math concepts and find other alternatives to solving and thinking about basic math problems...[S]eeing math being manipulated in a broader context helped me especially during the first week of my calculus 1 class!!" In reflecting on the campus data project, another student reported, "I never really knew how to explain graphs before so I learned a lot about this form of story-telling."

Some of the student comments are less about specific activities and more about habits of mind that students developed in the course. One CUBE participant wrote, "I got the chance to develop endurance and not be deterred by hard problems and to seek help when I am confused." Another student, when asked to reflect on whether CUBE helped their quantitative skills, responded that the program "put me in the right mindset going into college."

Even after completing the program, some students expressed their wariness of math, confirming that CUBE reaches some math-averse students. One participant captured the sentiment well: "It was a great refresher and introduction on precalculus and trigonometry concepts, and I'm not the biggest fan of math, but I really appreciated and enjoyed the mental challenge." Comments like these are of particular note given that participation in CUBE is voluntary.

As a review of the bridge program literature indicates, direct assessment of the impact on student academic outcomes is challenging. This is particularly true for our program as it is not designed to be preparation for specific math or science courses, nor is it designed to serve only students who plan to major in quantitatively rich fields. Our goal is to strengthen student quantitative skills and prepare them for the academic experience at Carleton broadly.

Course grades are an easy place to look for impact, but course grades encapsulate many factors beyond quantitative skills preparation. We chose to look at student grades in courses with a quantitative reasoning encounter (QRE), regardless of discipline, to see if there was any difference between the grades that CUBE and a demographically matched group of students earned. We did not expect that we would see any significant difference given the broad scope of our program and the limited number of quantitative skills which we focused on developing. Consistent with our expectations, we do not see any difference (Fig. 3). QRE courses at Carleton vary greatly in the extent and sophistication of quantitative skills required, as is appropriate for their respective disciplines and positions in the curriculum. Thus, it may not be informative to combine grades and enrollment data across all of these courses and pathways. 


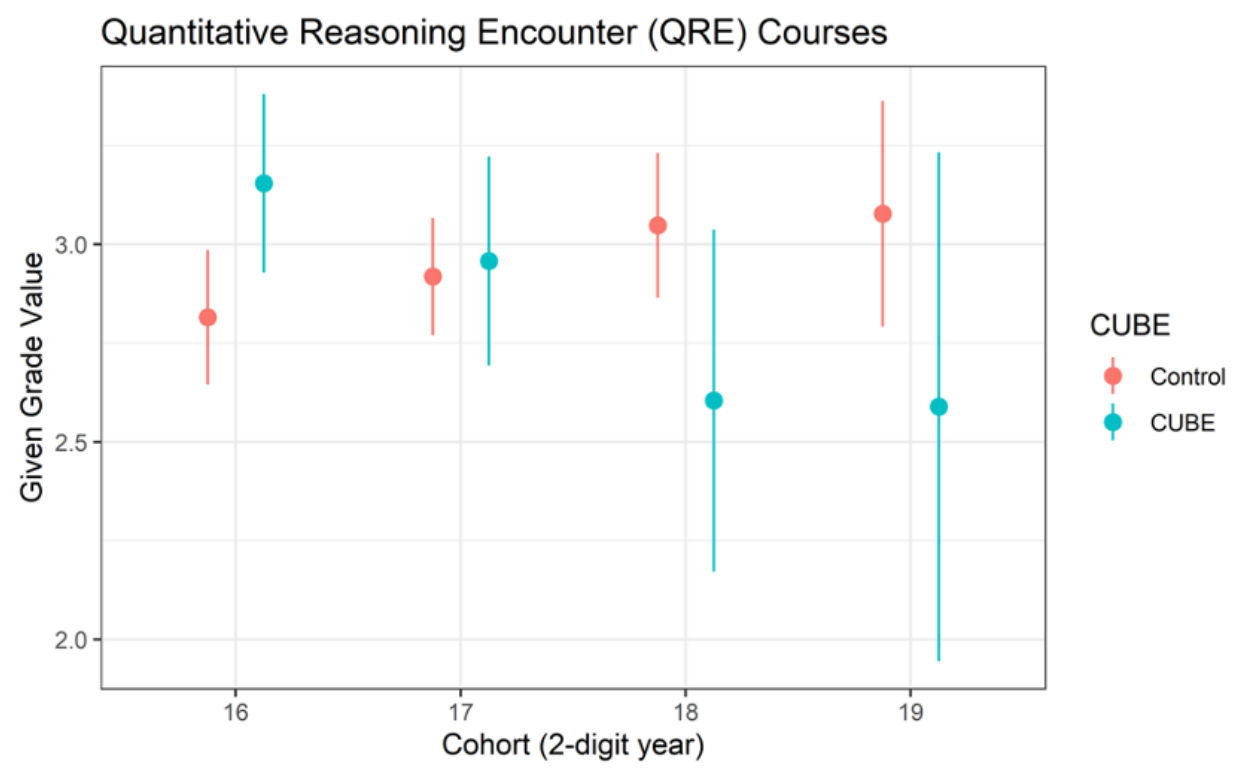

Figure 3. Grades in courses that satisfy the quantitative reasoning encounter graduation requirement for CUBE students and a demographically-matched group of students, by cohort year. The grade weightings are: $\mathrm{A}=4.0 ; \mathrm{A}-=3.67 ; \mathrm{B}+=3.33 ; \mathrm{B}=3.0 ; \mathrm{B}-=2.67 ; \mathrm{C}+=2.33 ; \mathrm{C}=2.0 ; \mathrm{C}-=1.67 ; \mathrm{D}+$ $=1.33 ; \mathrm{D}=1.0 ; \mathrm{D}-=0.67 ; \mathrm{F}=0$.

In an attempt to narrow the range of courses considered, we focused on five common introductory courses across three departments that require students to use quantitative skills, and repeated the analysis, comparing the grades earned by CUBE students to a demographically matched group of students. The five introductory courses were Introductory Biology, Chemistry, Economics, and two Calculus I courses, Math 101 and 111. Math 101 Calculus with Problem-Solving is the most introductory course offered by the mathematics department at Carleton. This course offers face-to-face instruction five days a week instead of only three, with the additional two days dedicated to working on homework and developing problem-solving skills with a peer teaching assistant and the faculty instructor. Math 111 is a more standard Calculus 1 course that is taught three days a week, and it is strongly suggested (but not required) that students score sufficiently high on our math placement exam before enrolling. We did not find any significant differences in student grades in these courses, with the exception of Math 111, in which CUBE students did worse than the matched cohort ( 0.77 out of 4 GPA points, $n=23, p=0.01$ ). CUBE student grades in Math 101 were slightly higher than the matched cohort, but this difference was not statistically significant. We also did not see any significant difference when we looked at all courses that meet the college graduation requirement of Formal \& Statistical Reasoning (FSR), which are mostly in math, statistics, and computer science. These findings are not surprising, given that CUBE was not designed to be a "math prep" bridge program. However, the 
difference between CUBE student performance in Math 101 and Math 111 suggests that combining multiple avenues of additional support for quantitative skills development (i.e., CUBE and Math 101) may be effective.

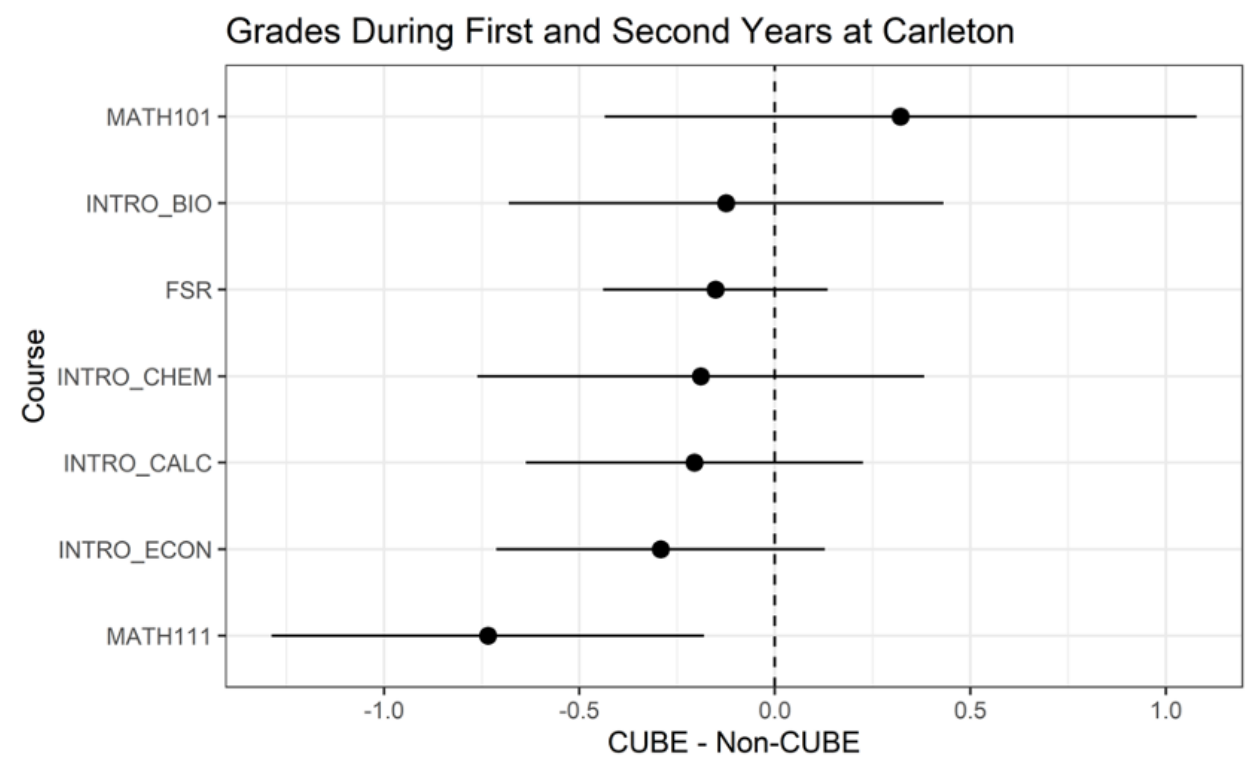

Figure 4. Difference in grades between CUBE students and a demographically-matched group of students for selected courses that are quantitatively rich. Math 101 and Math 111 are both introductory calculus classes, but Math 101 provides additional review and practice; the results from both courses are combined in the Intro_Calc result. FSR courses are courses that meet the formal and statistical reasoning graduation requirement and include computer science, math, statistics, and other abstract/theoretical quantitative methods courses.

In addition to grades, one can ask whether CUBE affects student enrollment in quantitative courses. We approached this question by quantifying the number of courses that each individual student attempted and the number of students in the cohort who enrolled in quantitatively rich courses. As with grades, we do not see an increase in the number of QRE or FSR courses that CUBE students enroll in (data not shown), nor do we see an increase in the proportion who enroll in the selected quantitatively-rich introductory courses discussed earlier (Fig. 5). However, this is not surprising given that students enter CUBE with major interests across the curriculum and pursue many pathways. This disciplinary diversity of CUBE students is a desired aspect of the program, not a weakness. It is not the mission of CUBE to guide students into more quantitative majors, but to make all majors more accessible regardless of previous mathematical preparation of students. In line with this goal, a future analysis will examine how student majors compare to the major interests they declared at the beginning of CUBE and the reasons for selecting their majors. 


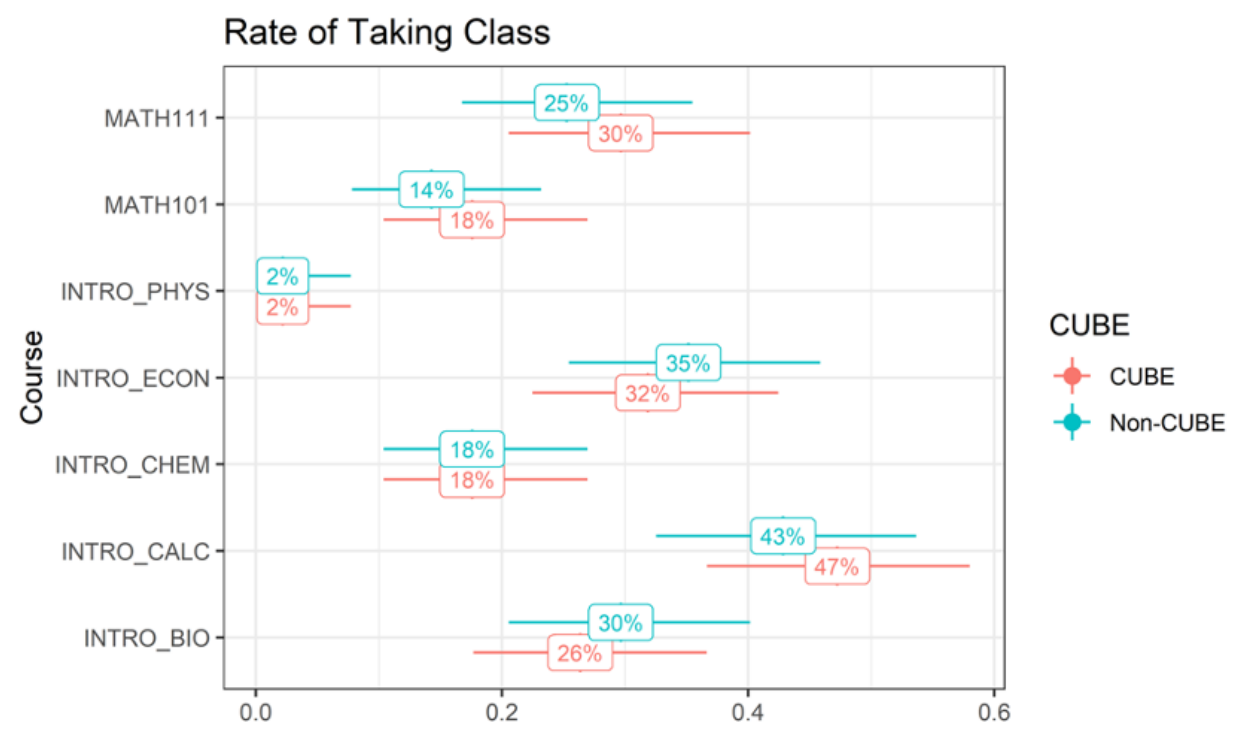

Figure 5. Percentage of CUBE participants (pink) and a demographically-matched group of students (turquoise) who enroll in selected quantitatively rich courses. Intro_Calc is the combination of Math 111 and Math 101 enrollments.

\section{Lesson 3}

Intentionally design for a mix of formal and informal interactions that include both small group and whole class opportunities in order to balance structured engagement with flexibility. In face-to-face classes, students naturally have opportunities for formal interactions with peers and the instructor through thinkpair-share, team-based learning, or other collaborative approaches, as well as informal interactions through in-class chatting or talking with peers or the instructor before or after class. We wanted to design our online course to have a similar mix of formal and informal interactions, and also to include a mix of whole class and small group interactions. In this way, we could intentionally build community despite the (largely) asynchronous nature of the course. Informal interactions occur through the Weekly CUBE prompts, which allow students to connect around topics that are not academic in nature. Formal interactions primarily occur around academic assignments, such as the POW and the campus data project. To accommodate as many schedules as possible, most of the formal involvement with academic assignments happens in their synchronous team meetings, which are led by the peer coaches. The only time that larger groups of students meet synchronously is for the alumni Q\&A sessions, or for other optional sessions the coaches help plan (e.g., a Q\&A with the dean of advising, movie nights, game nights). 
Making the expectations for engagement clear is important. For example, responding to the Weekly CUBE prompts, although designed to promote informal interactions, is required of students. Why? This demonstrates the importance of connecting with peers in the course, and provides a low-stakes way for students to stay engaged. However, to provide flexibility, students are only required to respond to $\sim 75 \%$ of the Weekly CUBE prompts during the program.

\section{Lesson 4}

Intensive early communication is critical to ensure that participants get started successfully. Bridge programs by definition occur during a time of transition, and online bridge programs, where students are not physically present on campus, need to be carefully tuned to that transitional moment. For example, students may be managing multiple email accounts—-personal email, high school email, and their newly created college email account. It is important to instruct students early and often to routinely check their college email account, and to email them consistently at only that address.

Prior to the official start date for the program, we recommend building in opportunities for students to test relevant technological tools. For CUBE, we use ALEKS as part of the application process so that students already have their ALEKS account set up before the start of the program. Additionally, each CUBE coach conducts a video conference call with the students on their team before the program begins, which prompts students to install relevant software ahead of time and allows the coach to spot issues with hardware (camera, microphone) and internet connectivity.

Once the official program begins, low-stakes engagement opportunities begin early. The Weekly CUBE prompts begin on Day 1; the teams meet synchronously on Day 2; and an assignment is due on Day 3. These multiple, early touchpoints give the instructor easy opportunities to reach out to students who do not respond, reveal obstacles to engagement that the student might be unaware of or uncomfortable bringing up, and encourage students to develop a consistent schedule for engaging with the primarily asynchronous program. This gives students practice managing their time with more independence than they likely had in high school but fewer scheduling demands than they will encounter in the fall when they are juggling multiple classes.

\section{Lesson 5}

Select, train, and support coaches strategically. In the scramble to launch the program in its first year, we did not specifically advertise and hire for the CUBE coach positions. Rather, we asked two students who were already working for Academic Technology to serve as CUBE coaches. Their experience working with technology and familiarity with the learning management system were skills that 
were important in the role. The coaches worked within the Academic Technology office, and the CUBE instructor met weekly with the coaches to plan for the upcoming week, discuss technical and academic challenges, and consider student progress in the course.

Because the coaches serve the triple role of providing technical, academic, and social support, after the first year of the program, we refined and formalized our strategy for selecting and preparing coaches. These students are hired jointly by Academic Technology staff and the CUBE program instructor. To broaden the pool of potential coaches, Academic Technology does not require that coaches have extensive technical support experience at the time of hiring, and through the interview process, we look for students who can relate to the varied backgrounds from which the CUBE students come. We try to recruit previous CUBE participants as coaches and have had at least one CUBE alum as a coach each year after the first year. More recently, we have developed a formal multi-day training program for the coaches that includes topics such as growth mindset, community building, how to ask and help students ask good questions, and problem-solving strategies. This training continues informally in weekly meetings between the instructional faculty and coaches throughout the six weeks of the course.

Another consideration in supporting coaches is whether to allow coaches to coach remotely. During the COVID-19 pandemic, coaches were remote out of necessity. This experience reinforced the benefits of having coaches be on campus, as they can more easily collaborate with each other and staff. Physical proximity facilitates more efficient troubleshooting of technical issues and communication between the instructor and coaches about program content and student progress. However, the cost of living on campus in the summer can be challenging for lowerincome students. In order to make the CUBE coaching position accessible regardless of family income, we would like to be able to pay for on-campus housing for student coaches in the future. This is not possible with the current program budget and presents complications related to financial aid, so we would encourage other institutions starting such a program to consider this early in the planning process.

\section{Lesson 6}

To make the faculty/staff workload manageable while still tailoring the program to the local context, use a mix of existing resources and activities that are designed by or for your institution. A variety of online resources and adaptive learning software have been developed to support student quantitative skills, and yet the tendency for faculty members is to custom-design materials, in part to give a sense of their own personality or the institutional context. This program never would have gotten off the ground if we had designed all the program materials from scratch. Rather, we identified existing resources that were flexible enough to allow 
us to incorporate them into the framework we developed, and then we developed wrapper materials that personalized the resources for our institutional context. For example, the POW and associated instructional videos were developed as part of the Yale ONEXYS program. To personalize these resources, we partnered with a Carleton faculty member from a different discipline each week to create a video describing how the topic was relevant either to their courses or research and edit the POW.

While existing resources and software provided focused review and practice, they did not provide more open-ended exploration and messy problems that students encounter in their quantitative courses at Carleton, which is why we designed the campus data project. By focusing our design efforts on the campus data project rather than building everything from scratch, the workload was manageable.

\section{Conclusions}

We have developed a bridge program that is a hybrid in many ways: summer and fall, online and in-person, asynchronous and synchronous, focusing on not only quantitative skill improvement but also non-academic skills necessary for academic success and community-building in college. When we set out to design this program, we found examples of online approaches to support student quantitative skills development as they bridge from high school to college, but those programs were often aimed at STEM majors. Also, the program descriptions focused primarily on the quantitative curriculum and not how the programs aimed to promote academic success skills or social connections, in combination with the quantitative skills development goals.

Our program is unusual because it is not aimed at preparing STEM-inclined students for Calculus; rather, it is aimed at preparing all students to engage in quantitative reasoning across the curriculum. This is in line with the QR coursework requirement on our campus. The diverse majors and pathways that students may take through college after CUBE have made data collection and measuring relevant outcomes a challenge. We have collected data about student course choices and grades in selected quantitatively-rich courses, but it is not clear that these are the most appropriate outcomes to measure. We do not find statistically significant differences in terms of course choices or grades in most of the courses we examined. We find that the combination of CUBE and our high-touch Calculus 1 course improves student grades, although not at a statistically significant level. The diversity that is inherent to our program, combined with our small sample sizes, makes quantifiable impact particularly challenging.

For measuring our community-building goals, we have relied heavily on qualitative evidence (end-of-program evaluations and focus groups). Students 
report building social connections that are important to them and persist beyond the program. We have found a positive relationship between CUBE and academic cocurricular interest and involvement, with CUBE students being more likely to be interested in doing research with faculty and to apply for intern- and externships. These outcomes suggest that students are not only aware of these opportunities, but find them accessible and relevant to their college journeys.

This program has made a significant impact in reducing the pre-matriculation credit disparity for students in the program, and we have outlined here our efforts to build community and support the development of academic success skills through this program. CUBE continues to evolve in response to feedback that we get from CUBE students and coaches, as well as faculty at our institution. Next steps that are current priorities include recruiting more diverse alumni to participate in the Q\&A sessions, considering how to improve the student selection process now that our school is ACT/SAT test-optional, and finding ways to enhance connections between CUBE participants and current students/staff/faculty who share interests or backgrounds. Nevertheless, the basic program model outlined here provides a solid foundation from which to build.

\section{Acknowledgments}

We would like to acknowledge Carleton College colleagues Andrea Nixon and Bill Altermatt for their help with program assessment and Janet Russell, now at Pomona College, who was instrumental in the original design and development of CUBE. We would also like to thank the reviewers of this paper for valuable feedback.

\section{References}

Ashley, Michael, Katelyn M. Cooper, Jacqueline M. Cala, and Sara E. Brownell. 2017. "Building Better Bridges into STEM: A Synthesis of 25 Years of Literature on STEM Summer Bridge Programs." CBE-Life Sciences Education, 16(4), es3. https://doi.org/10.1187/cbe.17-05-0085

Boettcher, Judith V., and Rita-Marie Conrad. 2016. The Online Teaching Survival Guide: Simple and Practical Pedagogical Tips. John Wiley \& Sons, 142145.

Brinkley, Kendra Woodberry, Falcon Rankins, Stevara Clinton, and Rosalyn Hobson Hargraves. 2014. "Keeping up with Technology: Transitioning Summer Bridge to a Virtual Classroom.” 2014 ASEE Conference Proceedings, 24.5.1-14.

Brown, Travis, Mary Coffey, Jennifer Rachford, and Hector Sambolín Jr. 2017. "The Pomona College Quantitative Pathways Project." Peer Review, 19 (2), 31-32. 
Chen, Xianglei. 2016. Remedial Coursetaking at U.S. Public 2- and 4-Year Institutions: Scope, Experiences, and Outcomes (NCES 2016-405). U.S. Department of Education. Washington, DC: National Center for Education Statistics. Retrieved 31 August 2021 from http://nces.ed.gov/pubsearch

Darby, Flower. 2019. "How to Be a Better Online Teacher." The Chronicle of Higher Education. Retrieved 31 August 2021 from https://www.chronicle.com/article/how-to-be-a-better-online-teacher/

Eblen-Zayas, Melissa, and Janet Russell. 2019. "Making an Online Summer Bridge Program High Touch.” Journal of College Student Development, 60(1), 104-109. https://doi.org/10.1353/csd.2019.0006

Eismann, Louisa. 2016. "First-Generation Students and Job Success." NACE Journal, 77(2), 11-18.

Jura, Matthew, and Ira Gerhardt. 2021. "Examining the Effectiveness of an Online Summer Bridge Course to Prepare Students for Calculus." PRIMUS, 1-9. https://doi.org/10.1080/10511970.2021.1919256

Lee, Jaekyung. 2012. "College for All: Gaps between Desirable and Actual P-12 Math Achievement Trajectories for College Readiness.” Educational Researcher, 41, 43-55. https://doi.org/10.3102/0013189X11432746

Reisel, John R., Marissa Jablonski, Hossein Hosseini, and Ethan Munson. 2012. "Assessment of Factors Impacting Success for Incoming College Engineering Students in a Summer Bridge Program." International Journal of Mathematical Education in Science and Technology, 43(4), 421-433. https://doi.org/10.1080/0020739X.2011.618560

Rutz, Carol, and Nathan D. Grawe. 2017. "How Writing Program Best Practices Have Transformed Carleton College." Peer Review, 19(1), 13-16.

U.S. Department of Education, Institute of Education Sciences, What Works Clearinghouse. 2015. Developmental Students in Postsecondary Education Intervention Report: Developmental Summer Bridge Programs. Retrieved 31 August 2021from http://whatworks.ed.gov

U.S. Department of Education, Institute of Education Sciences, What Works Clearinghouse. 2016. Supporting Postsecondary Success Intervention Report: Summer Bridge Programs. Retrieved 31 August 2021 from http://whatworks.ed.gov

White, Bernard, Eileen Patricia Mazzone, and Vicki L. Dominick. 2011. "An Online Alternative to the On-Campus Summer Bridge Program." 2011 ASEE Annual Conference Proceedings, 22.193.1-22.193.13. 